\title{
Romanceiro da Inconfidência: poder e literatura
}

\author{
Romanceiro da Indonfidência: power and \\ literature
}

Prof. Dr. Celso Leopoldo Pagnan

\begin{abstract}
Resumo: Este artigo tem como objetivo principal analisar o livro Romanceiro da Inconfidência, de Cecília Meireles, sob duas perspectivas, a literária e a jurídica. Isso porque a obra, para além de retomar literariamente um episódio da história do Brasil, também, indiretamente, empreende uma discussão em torno da questão jurídica na colônia (por extensão à perda das liberdades individuais em períodos ditatoriais). Procuramos, pois, dar ênfase aos aspectos da obra que tratam da oposição entre liberdade e opressão, tendo como ponto de fundo as Ordenações Filipinas.

Palavras-chave: Direito. Literatura. Cecília Meireles.

Abstract: This article has as main objective to analyze the book of Cecília Meireles, Romanceiro da Inconfiência, from two perspectives, the Literary and jurisdictions. That's because the poem incorporates a fact of the story of Brazil, and indirectly initiates a discussion around the issues in separate legal Colony (for extensive loss of individual freedoms in dictatorial periods). We seek, therefore, give emphasis to aspects of the poem dealing with oposio between freedom and tyranny, having as a background the Ordernações Filipinas.

Keywords: Law. Literature. Cecília Meireles.
\end{abstract}

\section{Introdução}

O presente artigo se insere em um projeto mais amplo que é o de propor uma pesquisa em torno das relações que podem ser estabelecidas entre o texto literário e o jurídico em três frentes principais: a presença do direito positivo em diferentes obras literárias, a recorrência a técnicas literárias na redação de códigos jurídicos e a consequente semelhança entre os processos interpretativos, de ambos os universos, por parte do leitor. Embora a ênfase da pesquisa seja a análise da primeira frente, as outras duas serão recorrentes. O corpus compreende a análise de três obras: Canaã (1902), de Graça Aranha, Romanceiro da Inconfidência (1953), de Cecília Meireles, e Os sinos da agonia (1974), de Autran Dourado. Os três livros encerram questões de ordem jurídica. Enquanto os dois últimos versam, direta ou indiretamente, a

* Doutor em Letras.Universidade do Norte do Paraná. E-mail: celso.pagnan@unopar.br 
respeito da devassa causada pela Inconfidência mineira, o primeiro trata de um julgamento de uma moça negra, pobre, acusada de infanticídio. Aqueles recuperam, pois, o contexto das Ordenações Filipinas, especialmente o livro V, ao passo que Canaã tem como referência o Código Penal da República, promulgado em 1890. O que se pretende é analisar e comparar até que ponto os textos literários refletem as codificações jurídicas, e como são meios de levar o leitor a refletir sobre a organização social, sobre o que é justo e o que é a democracia.

Podemos estabelecer uma distinção até certo ponto óbvia: Literatura é ficção, e Direito meio de produzir as normas para o convívio social no mundo real. Também é bastante óbvio que um escritor, para produzir um texto literário, tende a se basear na realidade (ainda que lhe seja permitido criar um mundo todo fantasioso, surreal, o ponto de apoio, a referência, será sempre o mundo real). O jurista ou o legislador, por sua vez, para produzir um artigo de lei, observa a necessidade de acordo com o que ocorre na realidade. O que intermedeia o papel de ambos, escritor e jurista, é a linguagem. Segundo Roland Barthes (2001), Direito e Retórica (literatura) têm origens comuns. No mundo clássico grego, em um julgamento sobre a propriedade de terras, recursos próprios da literatura foram utilizados para persuadir os litigantes. Há outros diversos exemplos que poderiam ser lembrados. Assim, a despeito dos objetivos pragmáticos serem diferentes, direito e literatura teriam vários pontos de contato. Há, nas letras, diversos pontos estabelecidos entre literatura e psicanálise, literatura e história, literatura e sociologia, mas faltava uma relação mais direta entre literatura e direito. Tal movimento desde os anos 70 se tornou comum nos EUA, e, no Brasil, tem se verificado o desenvolvimento, embora tímido, de uma aproximação entre os campos.

Godoy (2008) explicita os pontos de contato estabelecidos ao longo dos últimos quarenta anos entre Direito e Literatura, bem como demonstra os fundamentos que nortearam tal aproximação. O argumento básico é que há diversas obras literárias que problematizam deliberadamente tal aproximação. Apenas como exemplo, podemos citar O processo, de Franz Kafka, que analisa os efeitos da burocracia e das leis na vida dos indivíduos. É preciso sempre ter em mente dois pontos essenciais: "[...] literatura é uma instituição social que utiliza, como meio de expressão específico a linguagem - que é criação social”. (WELLEK; WARREN, 1955, p. 117). Assim também se apresenta o Direito, que tem uma função social óbvia e se expressa por meio de uma linguagem. A partir desse ponto, é que os defensores da aproximação entre Direito e Litera- 
tura desenvolve sua argumentação. Em particular Dworkin (2007), para quem o processo hermenêutico da literatura se aproxima e muito da hermenêutica jurídica. Em outros termos, os textos jurídico e literário são letra morta até o momento em que passam pela interpretação; o segundo se presta à reflexão da sociedade, ao passo que o primeiro à ordenação dessa mesma sociedade. Ambas as ações mediadas pela linguagem. E se a interpretação nem sempre é a mesma, a explicação se encontra nas condições contextuais. Tanto um texto literário, quanto uma norma jurídica podem sofrer modificações interpretativas conforme o momento, conforme o local, evidentemente que se respeitando os limites fornecidos pelo texto.

A sociedade é bastante complexa e a literatura tem como uma de suas funções a interpretação da realidade, ainda que por meio de um olhar limitado que é a do escritor individual. Ainda assim, ao construir personagens díspares, tem essa função facilitada tendo em vista que quer expressar os diversos discursos sociais. Dessa feita, o estudo literário é realizado, quase que por imposição, por meio da interdisciplinaridade. O direito, por sua vez, tende a congregar a média discursiva dos anseios sociais, uma vez que uma lei é criada a partir das discussões envolvendo setores diversos da sociedade, representada pelos deputados, senadores e juristas. Ora, considerando essa pluralidade de ideias tanto na concepção legislativa quanto no processo criativo literário, subentende-se a defesa dos valores democráticos.

O foco do presente artigo é o Romanceiro da Inconfidência, de Cecília Meireles. Escrito em 1953, tal livro se insere no interregno de duas ditaduras, quando se imaginava que o país poderia solidificar sua democracia. O Brasil estivera sob ditadura até 1945, tendo à frente o presidente Getúlio Vargas. Ironicamente, no ano da publicação do livro, o presidente, então eleito, era o próprio Getúlio Vargas. Desse modo, fica sugerido quão frágil era ainda essa democracia. Dessa feita, queremos demonstrar que a arte, em particular a literatura, podem estar a serviço da defesa e da manutenção de uma ordem democrática. O método para estabelecer as relações entre o contexto vigente, as leis expressas e as obras literárias é o comparativo. É bem verdade que teremos como base não uma relação mecânica, causal, e sim dialética, que estabeleça o diálogo entre as duas áreas da sociedade. 


\section{Romanceiro: uma visão jurídica}

A carreira literária de Cecília Meireles se dá com a publicação de Espectros, em 1919, mas sua maturidade como poetisa se concretiza em 1939, com o livro Viagens. Basicamente, procurou escrever poemas que abordassem questões existenciais, a efemeridade da vida, a afirmação da espiritualidade, enfim temas sem conotação essencialmente político-social, como ocorre com outros poemas. Por esse motivo, a publicação de Romanceiro da Inconfidência em 1953 deve ter causado estranheza a quem acompanhava sua produção poética, isso porque se trata de um livro de caráter político, ainda que o tempo fugidio esteja bem presente ao longo dos romances do livro. Até pelo título, é possível perceber essa intenção política e a própria temática do livro, ou seja, a Inconfidência ou Conjuração mineira, que se deu em fins do século XVIII, mais precisamente em 1789.

Na verdade, a narrativa do poema se inicia bem antes dessa data; faz referência à descoberta do ouro e de pedras preciosas nas Minas Gerais, à época ainda ligada à Capitania de São Paulo, tematiza também um pouco a vida do comendador João Fernandes, responsável pela extração de diamantes em Tijuco (atual Diamantina) e que se casou com uma negra alforriada chamada Chica da Silva, também referida no poema; o ponto alto do livro é a Inconfidência, com ênfase ao momento da delação, busca e captura dos inconfidentes e as respectivas punições.

Evidente que a autora não analisa ou tematiza todos os pormenores, mesmo porque estamos diante de uma obra literária e não de um estudo histórico, mas procura captar o que a história desses acontecimentos legou para a posteridade, até para seguir um dos pontos fortes de sua produção que é a captação da essência da vida. Conforme diz a própria Meireles (2005, p. XXV): "A obra de arte não é feita de tudo - mas apenas de algumas coisas essenciais".

Os romances seguem uma ordem cronológica ainda que fragmentada. Mesmo assim, é possível estabelecer relações entre a visão que se expressa no texto e os acontecimentos históricos. Por exemplo, verificam-se o ciclo do ouro e o do diamante. Em ambos, temos a dicotomia principal sob a qual se assenta o texto: escravidão e liberdade. Escravidão de negros e também dos colonos, subjugados às leis de Portugal, às Ordenações Filipinas; e liberdade, o sonho desejado e arquitetado desde o início, na figura do negro Chico Rei, por exemplo, que queria liberdade para ele e para seus pares, e a liberdade almejada pelos conjurados na segunda metade do século XVIII. 
O livro V, das Ordenações Filipinas, em seu Título 6, trata sobre os crimes de lesa-majestade. Basicamente, apresenta-se a legislação sobre o crime de traição ao Rei e ao Estado, considerado o pior crime se pode cometer. Interessante que em seguida compara-se esse crime à lepra, posto que tanto a doença quanto o crime não teriam cura de fato. Em seguida, passa a enumerar os oito tipos de traição. O que nos interessa mais de perto é o quinto tipo: "O quinto, se algum fizesse conselho e confederação contra o Rey e se Stado, ou tratasse de se levantar contra elle, ou para isso desse ajuda, conselho e favor." (ORDENAÇÕES, 2009, p. 1153).

Em seguida, as Ordenações passam a tratar das penalidades para esse crime de lesa-majestade. Resumidamente, trata do confisco dos bens, da morte para sempre (apesar da tautologia, a ideia era enfatizar que tudo o que se conquistara, como honra, bens, títulos, perderia valor, incluindo os descendentes homens) e do degredo.

E sendo o commettedor convencido por cada hum delles, será condenado que morra morte natural cruelmente e todos os seus bens que tiver no tempo da condenação, serão confiscados para a Coroa do Reino, postoque tenha filhos, ou outros descendentes, ou ascendentes, havidos antes, ou depois de ter commetido, tal malefício. (ORDENAÇÕES, 2009, p. 1154)

Para compor os vários momentos da história das Minas, a autora escolheu o gênero romance. São 85 com métrica e ritmo irregulares. Isso é, embora predominem as redondilhas (de cinco ou sete sílabas), há também versos com quatro, seis, oito, dez sílabas. Há também poemas nomeados por cenários e falas. Os primeiros para ambientar a cena, mostrar ao leitor onde se passa a história, é como em uma peça de teatro na qual o autor explica como deve ser preparada a cena. Quanto à fala, presta-se ao leitor para ter contato mais direto com as explicações e comentários do narrador.

Tais cenários, que situam os ambientes, e as falas, em que se tecem comentários diversos sobre o que se narra, se prestam ao eu que narra, o qual se revela distante dos acontecimentos; narra como quem recupera o passado e faz uma leitura desse mesmo tempo. Por exemplo, na fala inicial é como se o eu do poema, passeando pela Ouro Preto atual, buscasse inspiração e marcas para entender o passado, descobrir nos interstícios da história, aspectos que permitam uma interpretação sob olhar moderno. 
Prof. Dr. Celso Leopoldo Pagnan

Aqui, além, pelo mundo,

Ossos, nomes, letras, poeira...

Onde, os rostos? Onde, as almas?

Nem os herdeiros recordam

Rastro nenhum pelo chão. (2005, p. 5)

Em conferência proferida em 1955, exatamente na cidade de Ouro Preto. sobre o livro publicado há dois anos, a autora diz ter se sentido impelida a escrever sobre o tema, eram como fantasmas a invadir sua vida, como se pedissem para que ela contasse a história do que ocorrera em Minas. A própria explicação do porquê escrever sobre o tema tem um quê de literário, fantasioso. Ainda assim, revela um importante aspecto: o fato de que algumas histórias simplesmente não terminam; seu significado ecoa nas construções, na memória coletiva, na imagem construída de um herói nacional como Tiradentes. E é a partir dessas considerações que inicia os romances:

O passado não abre sua porta e não pode entender a nossa pena. mas, nos campos sem fim que o sonho corta vejo uma forma no ar subir serena: vaga forma, do tempo desprendida. É a mão do Alferes, que de longe acena. (2005, p. 11)

É, pois, da perspectiva de alguns personagens da história das Minas, particularmente da Inconfidência, que o eu lírico faz suas considerações e propõe questionamentos, cujas respostas cabe ao leitor buscar. Em vários momentos, interrompe a narração para tecer algum comentário ou analisar um acontecimento, como, por exemplo, ocorre no Romance III.

O conde jurou no Carmo

Não fazer mal a ninguém.

(Vede agora pelo morro

Que palavra o Conte tem!

Casas, muro, gente aflita

No fogo rolando vêm!) (p. 23)

\footnotetext{
Todas as demais referências ao livro pertencem à mesma edição: MEIRELLES, Cecília. Romanceiro da Inconfidência. 3a. ed. Rio de Janeiro: Nova Fronteira, 2005 
A estrofe se refere ao Conde de Assumar, Dom Pedro Miguel de Almeida Portugal, que governou com mão de ferro a Capitania de São Paulo e das Minas do Ouro até 1721, quando Minas foi oficialmente desmembrada da Capitania de São Paulo e tornou-se independente. O trecho também revela a preocupação da autora em poetizar a história das Minas não apenas em seu momento emblemático, que foi a devassa dos Inconfidentes, e sim mostrar como a região foi construída e que personagens contribuíram para isso. Além disso, ao contar a história de Minas, o leitor percebe que não foi nada idílica, e sim marcada por traições, roubos e desmandos dos poderosos para enriquecer ainda mais.

Com efeito, entre os romances I e XIX, o leitor toma contato com alguns personagens importantes da história das Minas. Além do próprio Conde de Assumar que é referido no Romanceiro como traidor ao dizer que nada faria contra revoltosos de 1720, e no entanto manda atear fogo em suas casas no distrito de Vila Rica (Ouro Preto), conforme se verifica na estrofe citada acima.

Essa revolta é explicada pelos historiadores como uma de tantas a respeito dos impostos sobre a extração do ouro e também sobre as leis portugueses que regulamentavam o extrativismo, as quais eram excludentes. Felipe dos Santos, líder da Revolta, foi enforcado e esquartejado, como seria também o Alferes Joaquim da Silva Xavier, o Tiradentes, por ocasião da Inconfidência. Embora parecidos, os episódios não têm o mesmo significado, uma vez que Felipe era português de origem e não liderara a revolta com fins emancipatórios. De qualquer modo, o caso é referido para anunciar o que veria depois e para ilustrar uma prática comum na corrida pelo ouro nas Minas Gerais.

Morreu Felipe dos Santos

E, por castigo exemplar,

Depois de morto na forca,

Mandaram-no esquartejar! (p. 24)

E adiante, no mesmo Romance $\mathrm{V}$ :

Dentro do tempo há mais tempo,

E, na roca da ambição,

Vai-se preparando a teia

Dos castigos que virão: 
Os casos de revolta são muitos. Do mesmo modo que a Coroa portuguesa exige o pagamento do quinto do que é extraído em pedras preciosas e ouro, os escravos e trabalhadores contratados, quando podem, desviam seu quinhão. O narrador relembra o caso, por exemplo, do Chico - Rei, um escravo que procurara lutar contra a escravidão e a submissão negra de maneira mais sutil, sem necessariamente pegar em armas. Primeiro, começara a esconder ouro pelo corpo e, aos poucos, foi juntando o suficiente para comprar sua carta de alforria. Procurou alforriar diversos companheiros dessa forma. Em outras palavras, roubava para comprar o que haviam lhe roubado: sua liberdade. Depois, associou-se à Igreja, e passou a dar dinheiro para a construção da igreja dedicada à Santa Ifigênia, princesa da Núbia (Etiópia), que teria se convertido ao cristianismo por influência das pregações de São Mateus.

Santa Ifigênia levanta o facho,

Procura a mina do Chico-Rei:

Negros tão dentro da serra negra

Que a Santa negra quase os não vê. (p. 33)

Adiante, a partir do Romance XIII, narra-se a vida de Chica da Silva, escrava alforriada que veio a se casar com o Contratador João Fernandes, homem poderoso do Tijuco (hoje Diamantina). O objetivo é mostrar que a ordem portuguesa não era inteiramente respeitada, uma vez que havia a proibição do casamento entre homens livres, brancos e negros escravos. Mesmo assim, Fernandez desafiou as leis do seu tempo para casar-se com Chica da Silva, imortalizada em filmes, novelas, ainda que nem sempre retratada da maneira mais próxima da realidade. Outro objetivo é referir-se, mais uma vez, à maneira imperialista de lidar com o extrativismo. Fernandes é interpelado pelo próprio governador das Minas, D. José Luis de Meneses, que governou a Capitania entre 1768 e 1773, para cobrar-lhe os impostos devidos. Porém, o

\footnotetext{
A partir de 1740, era preciso um contrato com a Coroa Portuguesa para explorar o ouro ou os diamantes nas Minas Gerais. "Coube o primeiro contrato para extração dos diamantes a João Fernandes de Oliveira. [...] A arrematação abrangeu um período de 4 anos, de $1^{\circ}$ de janeiro de 1740 a 31 de dezembro de 1743”. (HOLANDA, org., 1993, p. 395). Esse João Fernandes era o pai do João relatado no poema; ficou como contratador (explorador de diamantes) entre 1758 e 1771, quando o Marquês de Pombal, para evitar roubos, criou a Real Extração e extinguiu os contratos. 
que se procura revelar é que, na verdade, o governador vem para expropriar Fernandes de seus bens, a mando do Marquês de Pombal.

Fala o conde de má morte:

- Ordens são, que hoje recebo...

Fala o Conde mui fingido:

- Padece por vós meu zelo:

De um lado, o dever de amigo,

Mas, de outro, a lealdade ao Reino..

João Fernandes não responde:

Ouve e recorda em silêncio

O que the dissera a Chica,

Em tom de pressentimento.

Como as palavras se torcem,

Conforme o interesse e o tempo! (p. 55)

Fernandes foi enviado de volta a Portugal, sem mais voltar ao Tijuco. Morreu em Lisboa no ano de 1779.

Trata-se, portanto, de outra situação que contextualiza os tempos das Minas, da extração, do engano, da cobiça, da traição. O Romance XIX encerra esse primeiro momento do livro e serve como prenúncio daquilo que irá se narrar doravante, que, segundo a perspectiva do narrador, será ainda mais terrível.

O livro na verdade não faz uma reavaliação crítica do que se passou em Minas. Toma como ponto de apoio a história oficial que foi sendo construída a partir de um estudo de Joaquim Norberto, intitulado História da conjuração mineira, de 1873, e no início da República, em 1890, com a oficialização do dia 21 de abril como dedicado ao Tiradentes. Por outro lado, Meireles usou o termo inconfidência no lugar de conjuração, sabendo-se que o primeiro denota uma falta de fé, uma descrença dos súditos, da perspectiva dos colonizadores portugueses, ao passo que o segundo denota uma conspiração que indica uma insatisfação da perspectiva do colonizado.

Os historiadores concordam que a insurreição não foi exatamente um processo bem articulado, feito por letrados, mas antes por pessoas descontentes com a forma de governar de Portugal. Tal descontentamento encontrou no Alferes Joaquim Xavier uma síntese e um divulgador, posto que colaborou para angariar novos adeptos e formar uma ampla rede de aliança. Também por isso, 
e por sua menor força política, acabou sofrendo muito mais no processo ao ser condenado à forca e a ser esquartejado como era de praxe à época. O mesmo castigo de Felipe dos Santos em 1720, conforme previa os itens dispostos no livro V das Ordenações filipinas.

Outro aspecto que confirma a obediência do livro aos preceitos erigidos é que Joaquim Norberto colaborou para a construção do mito Tiradentes relacionando-o à figura de Jesus Cristo, traído por um dos seus. Também o alferes, conforme a história construída, fora traído por um dos inconfidentes, Joaquim Silvério. Diz Norberto:

Retirou-se o alferes desconsoladíssimo do palácio e em caminho encontrou-se com o seu mau gênio. Como querendo patentear-se mais seu amigo do que o mesmo vice-rei, que era da escola do visconde de Barbacena acerca dos sagrados deveres da amizade, avisou-o o coronel Joaquim Silvério que tivesse conta em si, que se retirasse, pois que o vice-rei, informado de suas práticas, andava com grande cuidado sobre ele, e mais dia menos dia seria preso. Era o beijo do Iscariota! Com a bolsa recheada do preço da traição vinha sentar-se Judas à mesa de Jesus Cristo. (SILVA, apud SERELLE, 1999, p. 191).

Não queremos ir contra os documentos e o discurso de historiadores que comprovaram a participação de Silvério para o início da devassa, apenas discutir a perspectiva que norteou a autora de o Romanceiro.

Melhor negócio que Judas

Fazes tu, Joaquim Silvério:

Que ele traiu um simples alferes.

Recebeu trinta dinheiros...

- e tu muitas coisas pedes:

Pensão para toda a vida,

Perdão para quanto deves,

Comenda para o pescoço,

Honras, glórias, privilégios.

$\mathrm{E}$ andas tão bem na cobrança

Que quase tudo recebes! (p. 100)

Embora haja essa imagem de Silvério/Judas, ao que parece, porém, Joaquim Silvério não teria participado, com efeito, da Inconfidência, e sim 
ouvido falar pela boca de um e de outro e, sobretudo, pela boca do próprio Tiradentes, que, segundo consta, era muito falastrão.

De qualquer modo, em apoio a essa associação entre Cristo libertador dos homens, Tiradentes libertador do Brasil, traídos ambos, mortos ambos, há o fato de que o processo que deflagrou a devassa contra os inconfidentes se iniciou na Semana Santa de 1789. Uma coincidência bem utilizada pelos republicanos positivistas.

Nos romances XX e XXI, com que inicia a narração dos acontecimentos em torno da conjuração, vemos a contextualização dos aspectos culturais e filosóficos que deram o rumo à insurreição e do próprio modus vivendi da intelectualidade da época.

Os ideais iluministas, de valorização do raciocínio, da busca de novos conceitos, de liberdade de pensamento, foram absorvidas e divulgadas entre os intelectuais brasileiros e particularmente entre os inconfidentes. Nada, porém, de modo tão aprofundado uma vez que não havia imprensa no Brasil (o que, como se sabe, viria a ocorrer com a chegada de D. João VI ao Brasil em 1808, quando foi fundada a imprensa régia). Assim sendo, todo livro ou material deveria ser impresso em Portugal, sob a supervisão do governo imperial, por esse motivo as ideias francesas, inglesas, alemãs sobre liberdade, preponderância da razão, reforma político-econômica, enfim, que visavam à construção do sujeito esclarecido encontraram eco aqui, mas sem grande aprofundamento pelas próprias condições locais. Em resumo, “[...] não foi uma insurreição de letrados [a despeito da participação de poetas árcades, como Cláudio Manuel da Costa e Alvarenga Peixoto], mas de homens descontentes visando a sacudir o jugo português".

No "Romance XXI ou das idéias", o leitor tem um painel geral desse contexto, além de novos comentários do narrador:

\footnotetext{
"A sua atenção (do Tiradentes) dirigiu-se principalmente àqueles que tinham motivos específicos de queixa contra a administração portuguesa, destacando-se, entre eles, os devedores do Erário Régio. Foi assim que a notícia do levante [...] chegou ao conhecimento do Coronel Silvério dos Reis, contratador que devia grossas somas à Fazenda Real”. (HOLANDA, org., 1993, p. 400. Cf. Inquietação revolucionária no Sul: conjuração mineira).

${ }^{4}$ Ibidem, p. 404. 
Prof. Dr. Celso Leopoldo Pagnan

Os estudantes que partem.

Os doutores que regressam.

(Em redor das grandes luzes,

há sempre sombras perversas.

Sinistros corvos espreitam

pelas douradas janelas.)

E há mocidade! E há prestígio.

E as idéias. (p. 65)

Na literatura, houve uma proximidade com esse movimento, excluindo-se a preocupação cientifica. Embora o arcadismo seja caracterizado como um movimento alienado pela temática bucólica e por retomar temas e motivos da Grécia clássica, o fato é que no período tivemos a publicação de importantes textos. O mais famoso é o poema Cartas chilenas, atribuído a Tomás Antonio Gonzaga, em que critica, indiretamente, o então governador das Minas, Luís da Cunha Menezes (1783-1788), além de um poema lírico, Marília de Dirceu, em que Gonzaga celebrizou versos amorosos dirigidos à sua amada, Maria Joaquina Dorothéa de Seixas, a Marília. Ainda que seja uma obra poética, uma obra baseada na imaginação do poeta, é possível acompanhar, pela leitura dos poemas do livro, a trajetória do relacionamento entre Gonzaga e Joaquina, inclusive o rompimento, quando o poeta é preso acusado de ser um inconfidente e degredado para Moçambique. No continente africano, Gonzaga reconstruiu sua vida e casou-se com a filha de um mercador de escravos.

Isso tudo é narrado em romances aqui e ali.

No Brasil, o Arcadismo se desenvolveu muito mais em Minas, graças exatamente à extração do ouro, que deu à Capitania certa riqueza e propiciou a formação de uma elite intelectual.

Pois bem, após os romances XX e XXI em que expõe esse contexto todo, o narrador nos romances seguintes trata dos eventos que, em sequência, culminaram na inconfidência, busca/captura, devassa, degredo e morte de vários acusados, em especial do Tiradentes. A começar pela morte em 1788 daquele que seria o sucessor de D. Maria I, a louca. Seu filho, o príncipe D. José Francisco, morre doente. No entanto, conforme sugere o narrador, apoiado nas conjecturas da época, o príncipe que poderia trazer paz à Colônia por suas ideias libertárias talvez tenha sido assassinado: 
Já plangem todos os sinos, Pelo Príncipe, que é morto. Como um filho de Rainha Pode assim morrer tão moço? Dizem que foi de bexigas; De veneno - dizem outros Que lhe deram os ministros Para o não verem no trono. Triste ano para a esperança, Este ano de 88! (p. 72)

Com isso, não haveria outro caminho que não a luta dos colonos. Reúnem-se, cria-se a bandeira, palavras de ordem se resumem no princípio da liberdade, pessoas são chamadas a participar, conspira-se por todo lugar. A dicotomia central do livro pode ser facilmente visualizada: opressão/escravidão versus liberdade.

Todo o processo se intensifica nos romances XXVI e XXVII em que o leitor, embora saiba já o que vai acontecer ao alferes Joaquim da Silva Xavier, é levado a passear pelas Gerais para também sonhar a liberdade que poderia resolver o problema do sofrimento e da pobreza dos colonos explorados pela Coroa portuguesa.

Conforme procuramos explicar anteriormente, há uma dicotomia bem visível em trechos específicos e no poema como um todo. Trata-se da oposição entre liberdade e a opressão, a escravização de corpos e pensamentos. O romance seguinte, o XXVIII, colabora para o movimento geral do texto ao mostrar uma das armas do status quo: a traição, personificada na figura de Joaquim Silvério. Como alento, a História repudia essa arma e glorifica os que lutaram do outro lado:

(No grande espelho do tempo, cada vida se retrata: os heróis, em seus degredos ou mortos em plena praça; - os delatores, cobrando o preço das suas cartas...) (p. 89) 
No “Romance XXXVII ou de maio de 1789”, temos a narração da captura de Tiradentes. Durou muitos dias, até ser preso no dia 10. Interessante que no mesmo mês de maio, na França, os iluministas conseguiram arregimentar a população que se insurgiu contra o clero, contra o despotismo, e Tiradentes era preso, de certa forma abandonado pelos seus pares.

\section{- Minas da minha esperança, \\ Minas do meu desespero! \\ Agarram-me os soldados, como qualquer bandoleiro. \\ Vim trabalhar para todos, e abandonado me vejo.}

Todos tremem. Todos fogem.

A quem dediquei meu zelo? (p. 107)

Pergunta-se o próprio Joaquim da Silva Xavier.

A literatura engajada tem como ponto central a reflexão sobre as injustiças sociais e como fundamento último a tentativa de transformação dessa mesma sociedade pela força da palavra. Cecília Meireles, apesar de ter produzido uma obra sem esse objetivo, no Romanceiro, ela seguiu o preceito. Claro que a transformação da sociedade brasileira não depende unicamente de um livro, de um escritor, mas sem dúvida que a força do conjunto pode levá-la a ser menos injusta. A indignação perpassa todo o Romanceiro, mas tem como ponto alto o Romance XLIII, em que o narrador transcreve como teria sido a linha de raciocínio para punir exemplarmente um, enquanto aos outros foram concedidos abrandamento ou mesmo encerramento do processo. Esse um, o Tiradentes, assim padeceu por não ter quem o protegesse de fato:

\footnotetext{
Esse que todos acusam, sem amigo nem parente, sem casa, fazenda ou lavras, metido em sonhos de louco, salvador que se não salva, pode servir de resgate. É o alferes Tiradentes. (p. 122)
} 
Salvador que se não salva, mais uma vez o discurso evoca a figura de Cristo, que dizia salvar a todos, mas não pôde livrar-se da crucificação. A mitificação de Tiradentes, a despeito de outros terem igualmente lutado pela liberdade, como Frei Caneca no início do século XIX, também enforcado, é retomada pelo discurso poético para ratificar tanto o mito como o princípio da libertação. Essa mesma construção do mito pela palavra poética é analisada pelo próprio poema. Isso é, o narrador reconhece a persuasão da palavra bem empregada, ainda mais pela boca de quem é proferida.

Assim se forjam palavras, Assim se engendram culpados;

Assim se traça o roteiro

De exilados e enforcados:

A língua a bater nos dentes...

Grandes medos mastigados. (p. 128)

A devassa atinge também os poetas conjurados. O Romance XLIX especula sobre a morte de Cláudio Manuel da Costa (1729-1789). Era juiz de direito, fora secretário da Capitania de Minas Gerais e tinha algumas posses. Apesar de bem estabelecido e gozando de prestígio na sociedade colonial, simpatizou-se pelo movimento inconfidente; mas, ao ser preso e interrogado, foi encontrado morto no dia 4 de julho na cela da Casa dos Contos, aonde fora levado dois dias antes. $\mathrm{O}$ narrador sugere ao leitor todas as possibilidades em torno de sua morte: teria se enforcado, fora assassinado com um punhal, deram-lhe veneno com a comida ou ainda nem morrera nesse dia, talvez tenha achado outro corpo em seu lugar e ele fugido com a ajuda do sertanista Inácio Pamplona para lugar ignorado e nunca mais localizado. Oficialmente, o poeta se suicidou; o poema quer, no entanto, mostrar que nem sempre a voz da autoridade é a verdadeira, que nem todo discurso oficial é necessariamente fiel aos fatos. Ainda que Cláudio Manuel da Costa tenha de fato morrido no dia quatro, a ideia é, pois, discutir como uma verdade pode se impor pela força da palavra, e pela força da posição social de quem diz.

Por aqui passou Pamplona,

[...]

Passou como um fugitivo,

e levava ao lado um vulto. 
Prof. Dr. Celso Leopoldo Pagnan

passou como um fugitivo:

e talvez seu companheiro

fosse o Doutor Cláudio, oculto. (p. 141)

E mais adiante:

Ai, palavras, ai, palavras,

Que estranha potência, a vossa! (p. 148)

No Romance LV, o leitor tem contato exatamente com a história do Dirceu, isto é, Tomás Antonio Gonzaga (1744-1810), autor do mais famoso poema lírico da época, Marília de Dirceu, dedicado à jovem Maria Joaquina Dorothéa de Seixas, com quem sonhava em se casar, mas foi impedido pelo degredo a que foi condenado por sua participação na Conjuração mineira. Assim como Cláudio, era homem das leis; tentou livrar-se da condenação. Foi enviado para Moçambique onde deveria cumprir 10 anos de degredo, ou seja, em 1802 poderia retornar ao Brasil, no entanto esqueceu-se de sua $M a-$ rília para, ironicamente, casar-se com a filha de um comerciante de escravos, chamada Juliana Mascarenhas de Sousa. A ironia, claro, reside no fato de Gonzaga participara de um movimento libertário, mas não se importou em ter como sogro alguém que mantinha a roda da história colonialista. A história de Gonzaga é retomada no Romance LXV, antecedido por um cenário. O caso é poetizado até o Romance LXXIII. Fala-se sobre o degredo em Moçambique, sobre a expropriação de seus bens, das doenças, da vida difícil, do casamento com Juliana, sobre a decepção amorosa de Maria Dorothéa, porém o objetivo principal é outra vez retomar a ideia da efemeridade do tempo, tema recorrente na obra de Cecília Meireles. No caso de Gonzaga, de todos os seus bens, o narrador diz ter lhe sobrado um par de esporas de prata. Trata-se, antes de uma metáfora: o sonho dourado, o sonho da liberdade virou prata, perdeu-se; no entanto, as esporas servem para dar movimento a um cavalo, fazê-lo trotar, ir adiante. Assim é o tempo, assim é a vida. O tempo é inexorável, vivemos o hoje, que vira ontem, e com esse ficam os sonhos, os desejos, os projetos de vida pessoal e coletiva. O que fica são poucas coisas.

- Quem compra este par de esporas que eram do poeta Gonzaga? 


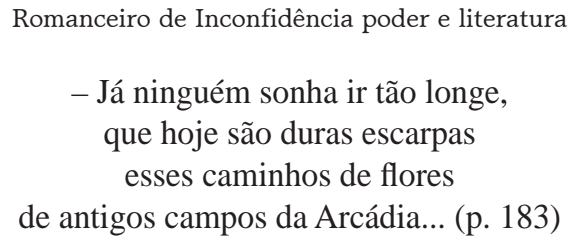

Além dos dois poetas citados, ainda um terceiro participou da Inconfidência: Alvarenga Peixoto (1744-1792). Também condenado ao degredo em Angola, morreu vitimado de uma febre maligna meses depois do início de sua pena. Narra-se sua história a partir do Romance LXXV, com destaque para sua esposa Dona Bárbara Eliodora, também poetisa, mas cujos textos se perderam no tempo. Era conhecida por ser uma mulher de grande beleza física e fiel aos princípios do marido. Teria escrito um poema em homenagem à filha, Maria Ifigênia, também lembrada pelo Romanceiro, no Romance LXXVII:

\author{
Triste menina a que estuda \\ com tão penoso cuidado... \\ Tratada como Princesa, \\ para quem estranho reinado? \\ Vai ver sua mãe demente, \\ vai ver seu pai degredado... (p. 217)
}

Quase no fim, narra-se a loucura e a morte de D. Maria I, que se deu em 1816. Era a rainha à época da Inconfidência e ficara louca em 1792. Por esse motivo, seu filho D. João tornou-se o príncipe regente, mais tarde aclamado como D. João VI, que veio ao Brasil em 1808, fugindo das guerras napoleônicas. Todo o episódio é muito significativo para marcar o fim de uma era e o início de outra. Como se sabe, a Conjuração mineira não foi o único movimento para tornar a colônia portuguesa independente, mas, pela construção mítica de Tiradentes, entre outros fatores, tornou-se a mais importante. Não é por acaso que no dia 21 de abril, lembra-se sua morte como homenagem aos que lutam por liberdade. Excluindo as figuras religiosas, como santos e Jesus Cristo, Tiradentes é a única personalidade da história a quem se dedica um feriado no Brasil. Todos os outros feriados comemoram feitos coletivos, como o 7 de setembro ou o 15 de novembro. 


\section{Conclusão}

O artigo, por fazer parte de pesquisa mais ampla, não deve apresentar ainda uma conclusão definitiva. Mesmo porque há um objetivo mais amplo que é o de discutir de que modo um texto literário se relaciona com o universo jurídico. Aqui, fizemos apenas alguns apontamentos iniciais, mas que sugerem tal foco. Ainda assim é possível mostrar que o poema, ao se encerrar com uma fala aos inconfidentes mortos, revela uma espécie de alento. O tempo passou, o sonho não se realizou para os conjurados, mas a ideia permaneceu, essa é a essência de tudo. E é essa essência, o sonho da liberdade, a despeito de uma ordenação ainda pouco justa com a coletividade, que fica nas calendas do tempo, matéria da poesia de Cecília Meireles.

$$
\begin{gathered}
\text { E aqui ficamos } \\
\text { todos contritos, } \\
\text { a ouvir na névoa } \\
\text { o desconforme, } \\
\text { submerso curso } \\
\text { dessa torrente } \\
\text { do purgatório... }
\end{gathered}
$$

Quais os que tombam, em crime exaustos,. quais os que sobem, purificados? (p. 239)

\section{Referências}

BARTHES, Roland. A aventura semiológica. S. Paulo: Martins Fontes, 2001.

DWORKin, Ronald. O Império do direito. 2. ed., S. Paulo: Martins Fontes, 2007.

GODOY, Arnaldo Sampaio de Moraes. Direito \& Literatura. Porto Alegre: Do Advogado, 2008.

HOLANDA, Sérgio B. de (org.). História geral da civilização brasileira:A época Colonial. Administração, Economia, Sociedade. Inquietação revolucionária no Sul: conjuração mineira. 7. ed., Tomo I, $2^{\circ}$ vol., Rio de Janeiro: Bertrand Brasil, 1993, p. 394-405.

MEIRELES, Cecília. Romanceiro da inconfidência. 3. ed. Rio de Janeiro: Nova Fronteira, 2005

ORDENAÇÕES FILIPINAS. Disponível em 
<http://www.ci.uc.pt/ihti/proj/filipinas/15p1153.htm> Acesso em 01 jun. 2009, p. 11521155

SCHWARTZ, Germano. A constituição, a literatura e o direito. Porto Alegre: Do Advogado, 2006.

SILVA, Joaquim Norberto de Sousa. História da Conjuração Mineira. Rio de Janeiro: Imprensa Oficial, 1948. Apud SERELLE, Márcio. No início da História da Conjuração Mineira: o fato e a ficção na construção da obra de Joquim Norberto de Sousa Silva. Gragoatá. Niterói, n. 6, p. 177-195, 1. sem. 1999, p. 191.

TRINDADE, André; SCHWARTZ, Germano (coord.). Direito e Literatura - O Encontro Entre Themis e Apolo. Curitiba: Juruá, 2008

WELLEK, René; WARREN, Austin. Teoria da literatura. Lisboa: Europa-América, 1955.

Recebido para publicação em 18 jun. 2009 Aceito para publicação em 03 nov. 2009 